\title{
Relevance of Health Economics in the Early Detection of Breast Cancer in Germany - the View of the Professional Association of Practicing Gynecologic Oncologists e.V. (BNGO)
}

\author{
Christoph Uleer ${ }^{\mathrm{a}} \quad$ Joachim Wagner $^{\mathrm{b}}$ Christina Moisidis-Tesch ${ }^{\mathrm{c}}$
}

${ }^{\mathrm{a} G y n e c o l o g i c}$ Oncology Group Practice Hildesheim and Mammographic Screening Unit Goettingen-Hildesheim, bynecologic Oncology Group Practice Voelklingen and Mammographic Screening Unit Saarland, ' ${ }^{\circ}$ ynecologic Practice Wiesbaden, Germany

\section{Keywords}

Breast cancer · Mammography · Mammography screening · Health economics · Outpatient setting

\section{Summary}

The introduction of the Mammography Screening Program (MSP) in 2005 has changed the early detection of breast cancer in Germany significantly. We analyzed the frequency and ensuing health care costs of mammograms performed for the early detection of breast cancer before and after the introduction of the MSP. Furthermore, we analyzed the influence of the MSP on the demographics of physicians (gynecologists versus radiologists) performing mammograms in Germany. Whereas the number of 'curative' mammograms has decreased since the introduction of the MSP, 2 million 'curative' mammograms per year are still being performed in addition to the 4.6 million mammograms performed annually in the MSP at an additional health care cost of approximately $€ 100$ million per year. Only $12 \%$ of screening and 'curative' mammograms are being performed and evaluated by gynecologists.

\section{Introduction}

The systematic early detection of breast cancer in Germany has changed significantly since the introduction of the Mammography Screening Program (MSP) in 2005. Screening mammograms, by definition performed on asymptomatic women, were not available to women covered by national health insurance prior to MSP. Under national health insurance, mammograms were considered 'curative' and could be performed only in the presence of a clinically suspicious finding or in women at increased risk of breast cancer based on family

\section{Schüsselwörter}

Brustkrebs - Mammographie - Mammographie-

Screening · Gesundheitsökonomie - Ambulanter Sektor

\section{Zusammenfassung}

Seit der Einführung des Mammographie-ScreeningProgramms (MSP) ist es zu einem Wandel in der radiologischen Brustkrebsfrüherkennung in Deutschland gekommen. In dieser Arbeit untersuchen wir die Häufigkeit und die Kosten der innerhalb und außerhalb des Screenings durchgeführten Mammographien und die sich wandelnde Rolle des Gynäkologen in der radiologischen Brustdiagnostik. Die Anzahl "kurativer» Mammographien hat seit der Implementierung des MSP abgenommen. Jedoch werden derzeit zusätzlich zu 4,6 Millionen Sreeningmammographien noch 2 Millionen «kurative» Mammographien pro Jahr in Deutschland durchgeführt, wodurch wiederum weitere zirka 100 Millionen $€ / J a h r$ an Kosten für das Gesundheitssystem entstehen. Nur noch $12 \%$ aller Mammographien werden von Gynäkologen erstellt und befundet.

or personal history. In order to offer early detection to a larger number of women, many mammograms were performed under the pretense of these indications (what has been referred to as 'grey' or 'opportunistic' screening), or alternatively, were performed on a private pay basis (table 1). In 2005, a nationwide MSP was established for women between the ages of 50 and 69. This program was extended successively throughout Germany and fully implemented by 2009. All women within this age group living in Germany receive a written invitation to a screening mammogram every 2 years and, currently, the participation rate is $54.5 \%$. There

\section{KARGER}

Fax +497614520714

Information@Karger.com

www.karger.com (c) 2013 S. Karger GmbH, Freiburg

$1661-3791 / 13 / 0081-0035 \$ 38.00 / 0$

Accessible online at:

www.karger.com/brc
Dr. med. Christoph Uleer

Facharzt für Frauenheilkunde und Geburtshilfe

SP Gynäkologische Onkologie

Bahnhofsplatz 5, 31134 Hildesheim, Germany

christoph.uleer@t-online.de 
Table 1. Definitions

\begin{tabular}{ll}
\hline Exam type & Indication \\
\hline Screening mammogram & $\begin{array}{l}\text { within the Mammography Screening Program (MSP), a mammogram performed on asymptomatic women } \\
\text { between age 50 and } 69\end{array}$ \\
'Curative' mammogram & $\begin{array}{l}\text { mammogram performed to clarify clinically suspicious findings or on patients at increased risk of breast } \\
\text { cancer } \\
\text { prior to MSP: 'curative' mammograms were also performed on asymptomatic women under the pretense } \\
\text { 'Grey' or 'opportunistic' screening }\end{array}$ \\
\hline
\end{tabular}

are 94 screening units throughout Germany, each usually guided by 2 lead physicians in charge ('Programverantwortlicher Arzt', PVA). They have a team of reading physicians ('Befunder') responsible for reading and evaluating the mammograms performed. The screening units are managed and supervised by 5 regional Reference Centers and a central Mammography Board ('Kooperationsgemeinschaft Mammographie'), responsible for reviewing the results and assuring the quality of the program. All mammograms performed on patients under national health insurance prior to the MSP and those currently performed outside of the MSP are considered 'curative' mammograms and are indicated for clarifying clinically suspicious findings or for patients at increased risk of breast cancer (table 1). In Germany, mammograms may be performed and evaluated by both radiologists and gynecologists possessing appropriate training and expertise. After receiving their training and passing licensing exams, these physicians may perform and evaluate mammograms and are required to undergo periodic quality reviews.

We examined the frequency and resulting costs of "curative' mammography before and after the introduction of the MSP in Germany. This analysis seems especially relevant from a health economic standpoint. A further goal of the analysis was to assess the change on the role of gynecologists (versus radiologists) in performing mammograms since the introduction of the MSP. In Germany, gynecologists are important in the early detection of breast cancer, since they evaluate women clinically and have the ability to perform diagnostic tests such as breast ultrasound or mammography in their office if they possess the necessary qualification. As members of the Society of Gynecologic Oncologists in Practice ('Berufsverband der Niedergelassenen Gynäkologischen Onkologen', BNGO) we wanted to examine the impact of the MSP on the role of gynecologists in breast cancer diagnosis.

\section{Materials and Methods}

In order to assess the frequency and costs of mammograms in Germany outside of the MSP during the study period, we performed a literature search and directly asked for information from the payment organizations. Approximately $90 \%$ of the German population is covered by national health insurance ('Gesetzliche Krankenversicherung', GKV), the remaining $10 \%$ have a private health insurance (PKV). The outpatient medical care provided by physicians to patients under the national health insurance is billed through the 'Kassenärztliche Vereinigung' (KV), an organization established on a regional (KV) and national ('Kassenärztlichen Bundesvereinigung', KBV) basis to coordinate the payment of physicians from the national health insurance for their services. The KV is comprised of an elected board of physicians who negotiate and coordinate payment contracts with national health insurance companies. Elements of medical care (procedures, therapies, counseling etc.) are assigned a billing code and a point value. The reimbursement in Euros varies on a regional basis depending on agreements between regional $\mathrm{KV}$ and national health insurance companies. We compared the number of 'curative' mammograms performed on patients in Germany covered by national health insurance between 2 study periods: January-June 2002 (before the introduction of the MSP) and January-June 2012 (after the implementation of the MSP). We then investigated the costs generated by the performance and interpretation of these 'curative' mammograms to the national health insurance companies during the 2 study periods in comparison to the costs of the MSP. Furthermore, to assess the role of gynecologists as compared to radiologists in the early detection of breast cancer through mammography in Germany, we obtained information from the KBV pertaining to the relative number of 'curative' exams performed by gynecologists and radiologists, respectively. Also, we obtained information from the central Mammography Board ('Kooperationsgemeinschaft Mammographie') about the annual costs of the MSP and the relative percentage of gynecologists (compared to radiologists) performing and evaluating mammograms in the Mammography Screening units. Finally, we analyzed the relative number of gynecologists (compared to radiologists) taking the theoretical and practical exams for the qualification for performing mammograms in Germany.

\section{Results}

Between January and June 2002, before the introduction of the MSP, 2,072,565 'curative' mammograms (at least 2 views per side) were performed on patients covered by national health insurance. Of these, $1,682,325$ were performed by radiologists and 390,240 by gynecologists. In contrast, during January and June 2012, 1,088,475 'curative' mammograms were performed outside of the MSP. Of these, 956,122 were performed by radiologists and 132,353 by gynecologists (fig. 1). We have not yet received information from the KBV about the costs of these 'curative' mammograms. Because the reimbursement for medical procedures varies across regions in Germany, we are unable to make an exact cost assessment at this time. Whereas in 2002 the reimbursement system underlay many variables, we can only estimate the costs for 'curative' mammograms in 2012 on the basis of an average $€ 26.29$ currently reimbursed for a mammogram ( 1 side in at least 2 views), which comes to $€ 100$ million $(2 \times € 25 /$ mammogram $\times 2,000,000$ mammograms per year). 


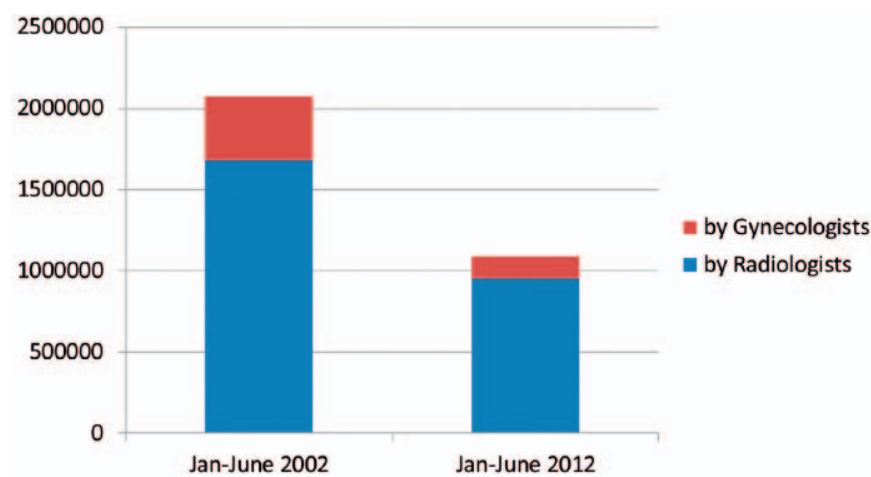

Fig. 1. Number of 'curative' mammograms performed in Germany before and after the Mammography Screening Program (MSP) (personal communication U. Casser, KBV, 11/2012).

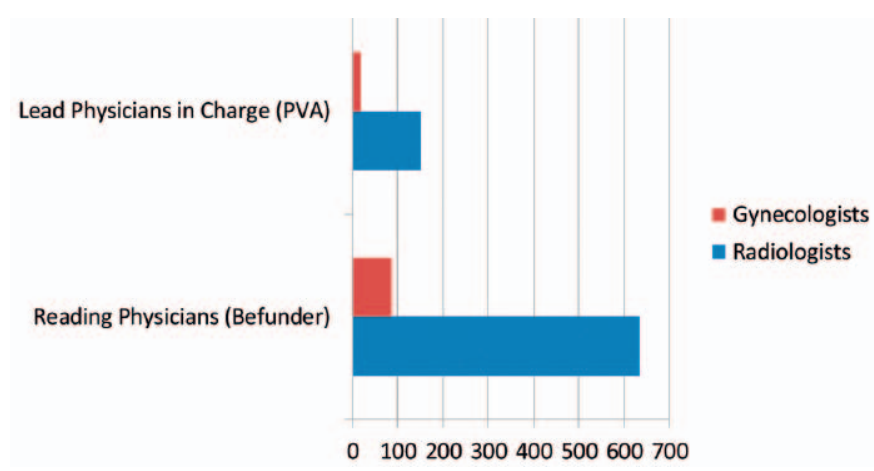

Fig. 2. Gynecologists and radiologists participating in the Mammography Screening Program (MSP) in Germany in 2012 (personal communication, V. Kääb-Sanyal, Central Mammography Board ('Kooperationsgemeinschaft Mammographie'), 11/2012).

According to the latest report from 2008/2009 about the MSP in Germany, 2.3 million women per year received mammography in screening centers. This corresponds to 4.6 million screening mammograms (at least 2 views per side) per year. We were informed by the central Mammography Board ('Kooperationsgemeinschaft Mammographie') that the costs for MSP were $€ 206$ million in the year 2010. This corresponds to $€ 45 /$ screening mammogram.

As can be seen in figure 1, while in $200219 \%$ of all 'curative' mammograms were performed by gynecologists, this number fell to $12 \%$ by 2012 . The central Mammography Board ('Kooperationsgemeinschaft Mammographie'), responsible for overseeing the MSP, informed us that in 2012 890 physicians were involved in the program, either as lead physicians in charge of screening units ('PVA') or reading physicians ('Befunder'). Of these, 12\% (18 lead physicians in charge and 152 reading physicians) were gynecologists and $88 \%$ (152 lead physicians in charge and 634 reading physicians) were radiologists (fig. 2).

The KV of the region Saarland informed us that in 2004 43 physicians took the theoretical exam to obtain the qualifi-

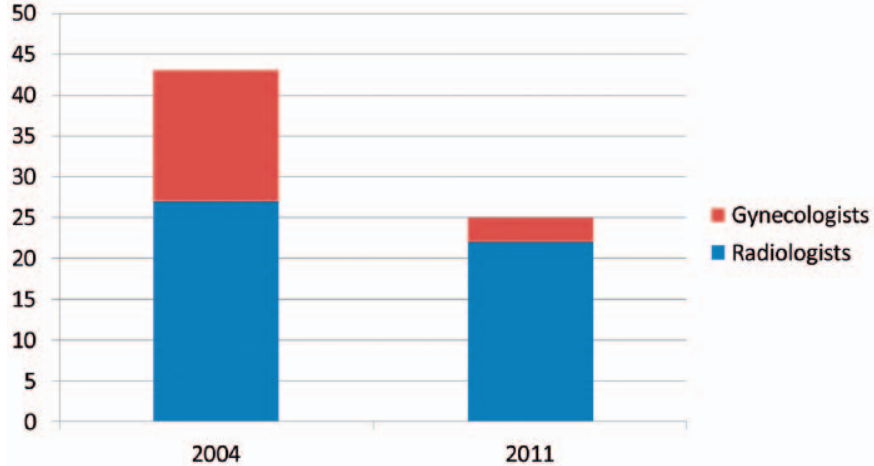

Fig. 3. Physicians taking certification exams for the performance of 'curative' mammograms in the region of Saarland (Personal communication M. Faggioli, KV Saarland, 11/2012).

cation for performing mammograms, 27 of these were radiologists and $16(37 \%)$ were gynecologists. In 2011, this number fell to 25 physicians, 22 radiologists and $3(12 \%)$ gynecologists (fig. 3). For the region Niedersachsen, there were no relevant differences in the number of theoretical exams taken by physicians toward mammography certification between 2004 and 2010 (18 vs. 21). However, we noted that in 2004, 97 mammography units sought approval by going through a quality control process while in 2010 this number had dropped to 54 centers. Data regarding whether these centers were run by radiologists or gynecologists were not available. No further data regarding this question were available from the KBV [1].

\section{Discussion}

Breast cancer is an important disease from the standpoint of health economics, due to its frequency among women in the population and the relative cost-intensive therapy. Mammography is currently the most important method of early breast cancer detection with respect to its evidence-based effectiveness. In 2001, the German Parliament proposed that the early detection of breast cancer in practice at that time, based on 'curative' mammography within the 'grey' or 'opportunistic' screening, was insufficient. They recommended that a nationwide MSP be introduced according to the European guidelines the major principles of which are widespread availability, no individual costs, high level of quality assurance, and the long-term aim of reducing breast cancer mortality [2]. Following a majority vote in Parliament in 2002, this program was introduced in 2005 and has been fully implemented throughout Germany since 2009.

The debate which led to the replacement of 'grey' or 'opportunistic' screening by a nationwide MSP was not held with specific health care costs in mind, but rather with the political aim to generate a more effective system of detection of early breast cancer and to reduce the breast cancer mortality rate in Germany [3]. To our knowledge a cost-effectiveness analysis 
for Mammography Screening has not yet been performed and is not planned.

From a diagnostic standpoint, the current MSP has been shown to be more effective in detecting earlier stages of breast cancer compared to the past system of 'grey' or 'opportunistic' screening. According to the current evaluation report of the central Mammography Board ('Kooperationsgemeinschaft Mammographie'), the distribution of cancers screened in early stages is consistent with the European guideline recommendations: i.e., the rate of node-negative breast cancers detected in 2008-2009 was 79\% compared to 57\% between 2000 and 2005 at the time of 'grey' screening [4]. Furthermore the breast cancer detection rate in the first 2 years of the MSP was 3 times higher than the breast cancer incidence rate in the years 2000-2005, prior to the MSP. Finally, the incidence of interval breast cancers, a further assessment of quality, was similar to international rates [5]. With respect to these surrogate markers the proposed goal of the MSP - to decrease breast cancer mortality in Germany - will likely be reached after appropriate follow-up.

To estimate the cost-effectiveness of the current MSP, one can use models which calculate $\$ 10,000-15,000$ per life year gained [6]. Of note, the MSP offers potential cost savings because of its strict quality parameters including that only $3 \%$ of women should be recalled for further diagnostic tests and only $1.5 \%$ for a biopsy. Additionally, further costs may be saved by reducing the number of hospital admissions for open biopsies and by avoiding cost-intensive chemotherapies for smaller and node-negative breast cancers.

According to the latest report from 2008/2009 about the MSP in Germany, 2.3 million women per year received mammography in screening centers. This corresponds to 4.6 million screening mammograms (at least 2 views per side) per year. On the other hand, 4 million 'curative' mammograms were performed in 2002 before the introduction of the MSP, and 2 million 'curative' mammograms in 2012. Although the number of 'curative' mammograms went down by $50 \%$, these mammograms performed outside of the MSP still correspond to $30 \%$ of all mammograms performed on patients under national health insurance. We were informed by the central Mammography Board ('Kooperationsgemeinschaft Mammographie') that the costs for MSP were $€ 206$ million in the year 2010 (€ 45/mammogram). Because of regional differences in reimbursement for medical costs and lack of data from the KBV about costs prior to MSP, we can only estimate the costs of 'curative' mammograms in 2012 at approximately $€ 100$ million per year.

Taking these data into consideration, we question whether 'curative' mammography is currently being performed only for the intended indications of suspicious clinical findings and increased breast cancer risk, or whether a 'grey' screening is being continued parallel to the MSP. If so, this may be a reason for the low participation rate of $54.5 \%$ (which is clearly below the participation rate of $75 \%$ recommended by the
European guidelines) and might prevent the MSP from reaching the goal of breast cancer mortality reduction. A 'grey' or 'opportunistic' screening parallel to the MSP also has health economic implications, since the cost saving potential of the MSP cannot be sufficiently exploited if 'curative' mammograms are excessively performed beyond its intended indication. Gelder et.al. [6] performed a cost-effectiveness analysis for mammography screening in Switzerland and concluded that centralized screening is cost-effective only if mammograms performed outside of screening are significantly reduced [6].

Of note for the purpose of medical specialization, the central Mammography Board ('Kooperationsgemeinschaft Mammographie') informed us that only $12 \%$ of all physicians performing and reading screening mammograms currently are gynecologists. This corresponds to data from the KBV indicating that approximately $12 \%$ of 'curative' mammograms are being performed by gynecologists. It is unfortunate that this skill is no longer being learned by gynecologists who in Germany play a central role in the diagnosis and therapy of breast cancer. Moreover, there is a trend towards centralizing 'curative' mammograms in fewer centers as the overall number of physicians performing 'curative' mammography is also decreasing. For example, in the region of Niedersachsen, the number of gynecologists performing mammograms in 2012 was less than $1 / 3$ of that in 2002 , and the number of radiologists was approximately $50 \%$ lower. This trend is also seen in the decreasing number of physicians seeking certification for performing mammograms.

The introduction of the MSP and the centralization of 'curative' mammograms to fewer centers impact the training of young physicians in performing mammograms: whereas in the past mammogram training took place in radiology departments of teaching hospitals, as the number of mammograms performed in the hospitals decreases, young physicians are unable to complete their training for mammography. They should be offered mammography training by rotating from the teaching hospital to a mammography screening unit. Due to the high number of mammograms per year in a screening unit, an intense training period of 6 months is probably sufficient for a resident to learn to perform and read mammograms as well as to gain experience in clarifying suspicious findings.

\section{Conclusion}

Despite the introduction of a nationwide MSP, approximately 2 million 'curative' mammograms are still being performed in Germany yearly, which used to have the purpose of clarifying clinically suspicious findings or were intended for patients at increased breast cancer risk. This large number of 'curative' mammograms suggests that a 'grey' or 'opportunistic' screening is still ongoing parallel to the MSP. This impedes reaching the desired $75 \%$ rate of participation in mammography 
screening and leads to additional health care costs of approximately $€ 100$ million yearly. A cost utility analysis of the current system of the MSP with a coexisting 'grey' or 'opportunistic' screening is warranted with more exact data about the costs of screening and 'curative' mammograms. The authors hypothesize a significant cost reduction if all mammograms would be done in the MSP and all 'curative' mammograms would be limited to their original indication. Furthermore, since mammography diagnostic is gradually moving outside of teaching hospitals towards mammography screening units, it is advisable that residents in gynecology and radiology have broader access to learning rotations in mammography screening units.

\section{Acknowledgement}

We thank Jasmin Pourfard and Norbert Uleer (SU Göttingen-Hildesheim), Wolfgang Aubke and Vanessa Kääb-Sanyal (Kooperationsgemeinschaft Mammographie, Berlin), Ulrich Casser (KBV, Berlin), Ursula Flohr (KVN, Hildesheim), Manuela Faggioli (KV Saarland), Ulrich Beyer (medac, Wedel), Isabel Machill (PKV, Berlin), Robert Machill (IGPVA, Berlin), and Esther Uleer (Press Spokes Person German Bundestag).

\section{Disclosure Statement}

The authors do not have financial interests to disclose.

1 Qualitätsbericht der KV Niedersachsen 2010, 2.16-2.17.

2 European Guidelines for Quality Assurance in Breast Cancer Screening and Diagnosis. 4th ed. Luxembourg, Office for Official Publications of the European Communities, 2006. ISBN 92-79-01258-4.

3 Unterrichtung durch die Bundesregierung: Gutachten 2000/2001 des Sachverständigenrates für die konzertierte Aktion im Gesundheitswesen. Bedarfsgerechtigkeit und Wirtschaftlichkeit. Band III: Über-, Unter- und Fehlversorgung. MuK Medien- und Kommunikations GmbH Berlin. ISSN 0722-8333.

4 Kooperationsgemeinschaft Mammographie: Evaluationsbericht 2008-2009. Ergebnisse des Mammographie-Screening-Programms in Deutschland. Berlin, Februar 2012

5 Heidinger O, Batzler WU, Krieg V, Weigel S, Biesheuvel C, Heindel W, Hense H-W: Häufigkeit von Intervallkarzinomen im deutschen MammographieScreening-Programm. Dtsch Arztebl Int 2012;109:781-787.

6 De Gelder R, Bulliard J-W, de Wolf C, Fracheboud J, Draisma G, Schopper D, de Koning HJ: Cost effectiveness of opportunistic versus organised mammographic screening. Eur J Cancer 2009;45:127-138. 